\title{
Strategic and tactical price decisions in hotel revenue management
}

\begin{abstract}
Dynamic pricing techniques allow using a number of variables in a tactical way compared to standard catalogue prices. This study merges in a conceptual model the relevance of the tactical and the strategic dimension of these variables, classified according to their tangible, reputational or contextual nature.

To empirically validate the hypotheses, a database of 21.596 price observations was retrieved from booking.com. The study presents a hedonic price function, using the Shapley-Owen decomposition of the Rsquared to elicit the importance of each group of factors. Further, a hierarchical cluster analysis measures the presence of heterogeneity across operators.

The results show that online reputation is gaining importance over the traditional star rating. Despite the tangible variables remain of paramount importance, the findings suggest the relevant role of contextual variables in short-run price variations. The players operating in the tourism and hospitality industries should integrate these findings when designing pricing strategies.
\end{abstract}

Keywords: dynamic prices, competition, online reputation, hedonic pricing model, Shapley-Owen decomposition 


\section{INTRODUCTION}

During the last decade, the tourism and hospitality industries have evolved significantly, pushing the bar higher for operators trying to get a competitive advantage in the arena. The widespread use of new technologies and the highly competitive environment of the industry have in fact forced operators to look for ways to improve their long-term strategies as well as their short-term tactical approaches.

One of the main dramatic changes has occurred in the area of pricing, with the implementation of new ways to easily adjust prices in real time over the internet. According to GBTA (2014), different forms of pricing intelligence software have already been used by $22 \%$ of operators in the tourism and hospitality arena, allowing them to boost their profits and gross margins by $25 \%$ and $10 \%$, respectively.

After initial skepticism, dynamic pricing strategies are now accepted, although customers often think that these strategies are used only to increase firms' profit (Dixit et al., 2005; Garbarino and Maxwell, 2010). Under certain boundary conditions the use of these techniques gives benefits both to managers and customers (Dixit et al., 2008). If implemented appropriately, dynamic pricing allows patient customers to get convenient deals and companies to increase their revenues much more than fixed prices or heuristic methods (Ingold et al., 2000; Peterson, 2005). Without an appropriate implementation of these strategies, prices tend to be too high when there is scarce demand and too low when demand exceeds expectations (Sanjay, 2009). Some possible threats when adopting these strategies are brand image, long-term profits and the reactions of customers who can try to strategically avoid high rates (Kannan and Kopalle, 2001).

While different famous intermediaries, such as Ebay and Amazon, adapted innovative dynamic pricing mechanisms based on segmentation of clients, fidelity, and past consumption behavior, with the goal of maximizing profits, here the focus is on a type of price optimization based on the fluctuation of demand. This technique, called revenue management (Cross, 1997), is mainly applied in context such as tourism, travel and lodging industries where if the service is not sold it is lost, i.e., the product is perishable and demand is uncertain (Netessine and Shumsky, 2002). An analytical discussion of the different theoretical models of revenue management can be found in Talluri and Van Ryzin (2004), while Kimes and Wirtz (2003) focus their attention on the need to protect the "valuable" segments. Managing prices through revenue management also helps operators to allocate a higher amount of existing resources, and increases the value for customers (Grönroos and Ojasalo, 2004). In these recent years, due to the advances in new technology and the growing prevalence of online travel agencies, we are assisting at the development of new revenue models to dynamically manage prices. The tourism and hospitality industries are peculiar, as they have to constantly cope with segments with different elasticity of demand, product characteristics of intangibility and perishability, and often fixed capacity constraints (Bull, 2006). In this uncertain scenario, the role of pricing is to maximize sellers' profits by capturing consumer's product valuations (Kim et al. 2009).

The current study proposes a conceptual framework of the main determinants of dynamic pricing, by jointly examining strategic and tactical dimensions. To validate the proposed framework, the study supplements the 
theory with an empirical validation in the hotel industry. Specifically, to accommodate the need to measure the price evolution depending on the ongoing market conditions, the current study makes use of a hedonic pricing approach. As for the strategic dimension, the findings support the relevance of reputational factors, with an increasing importance of online customer reviews over traditional star rating. As for the tactical dimension, despite the tangible variables remain of paramount importance, the findings of the paper indicate the significant premium price that one hotel can obtain by exploiting different booking times and by considering its own market power in real time. By analyzing prices dynamically and investigating its strategic and tactic dimensions, the findings have rich implication for industrial agencies and enrich the extant hedonic pricing literature on hospitality services (Abrate et al., 2011; Espinet et al., 2003; Monty and Skidmore 2003; Rigall-I-Torrent and Fluvià, 2011; Thrane, 2007; Zhang et al., 2011).

The rest of the paper is structured as follows. First, we present the conceptual framework considering the previous literature and formulating the hypotheses of this study. Subsequently, we introduce the empirical model and present the results and a discussion of the findings. Finally, the implications for the tourism and hospitality industries conclude this paper.

\section{CONCEPTUAL FRAMEWORK}

Many variables and service attributes can influence the price level. With the goal of a better understanding of the range of factors that have the potential to influence prices and their evolution, this study develops a conceptual model that isolates three main types of variables: (i) tangible variables in the form of physical objective characteristics of the service sold; (ii) reputational variables, in the form of ratings/reviews provided by third parties; and (iii) contextual variables, such as the characteristics of the location and the competitive environment faced by the tourist operator. These three groups of variables consist both of a strategic (long-term) and a tactic (short-term) dimension, as illustrated in Figure 1. Thus, the price can be seen as the result of the combined interplay of these factors, whose relative importance might differ depending on what is more decisive for the consumer.

In this framework, we pay particular attention to the tactical dimension, as it is the one that is more volatile over time and where the single operator has the opportunity to rapidly react to other competitors' moves. To face this complexity, we analyze how dynamic pricing techniques can help to adjust prices in real-time depending on the ongoing market conditions. 


\section{Figure 1. Conceptual model.}

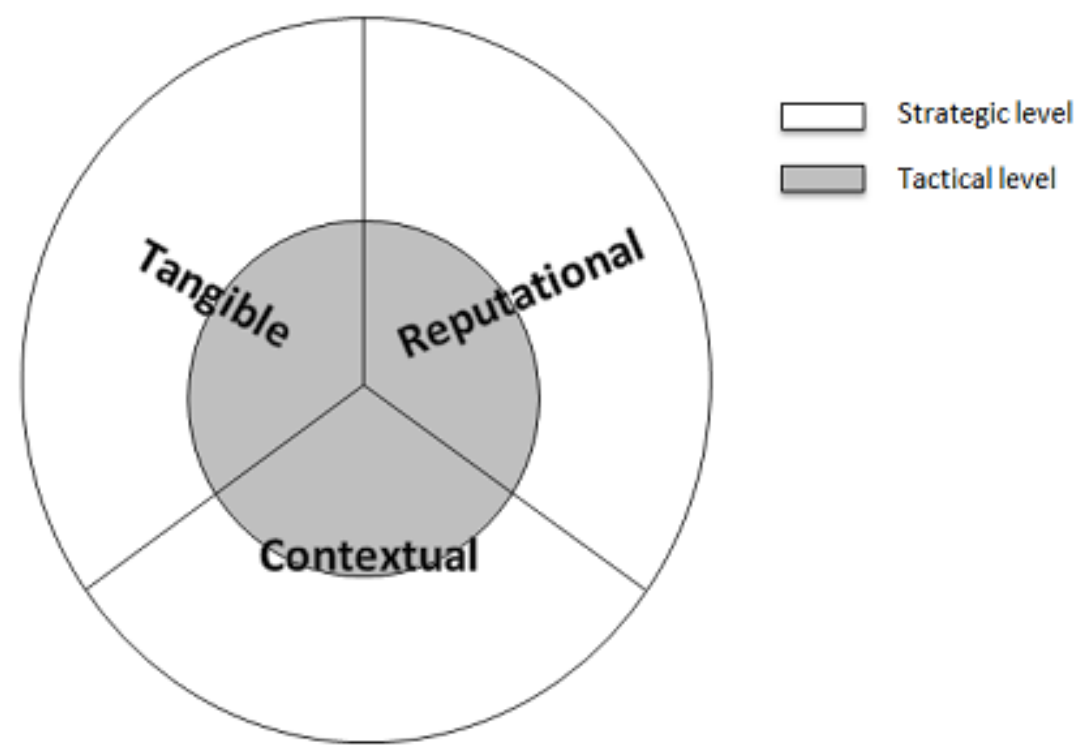

Tangible attributes. Tangible attributes are strategic in nature but they can also be used in a tactical dimension when the tourism service presents heterogeneous characteristics. In the travel industry, operators may offer free class upgrading depending on the availability of seats of the different classes. In the area of hospitality, a hotel with different types of rooms can tactically allocate them depending on the booking time or the target client. When looking at the specific contribution of tangible attributes, the number of rooms (Coenders et al., 2003; Roubi and Litteljohn, 2004), the room size (Monty and Skidmore, 2003) and the presence of a spa and wellbeing center (White and Mulligan, 2002) were generally considered to have an effect on hotel price. There are then other attributes that are used depending on the destination, such as the presence of congress facilities for more business-oriented locations (Abrate et al., 2011) and the presence of a pool for more leisure-oriented locations (Espinet et al 2003). More recently, it was highlighted how also the star rating of a hotel should be considered carefully, as it is an evaluation that already takes into account some of the tangible attributes of a hotel (Yacouel and Fleischer, 2012). The findings from these studies are contrasting. The cross-comparison of older studies indicates a divergent impact of facilities and amenities on price levels (Monty and Skidmore, 2003; Thrane, 2007; White and Mulligan, 2002). Whilst Thrane (2007) and Abrate et al. (2011) indicate a moderate effect on prices, White and Mulligan (2002) indicate a positive effect. At the opposite extreme, Monty and Skidmore (2003) do not identify any interaction with the price level. In light of these empirical findings, the influence on price levels has to be tested in relation to the total amount of facilities and amenities. A partial answer to this question comes from Zhang et al. (2011) who stress the importance of tangible attributes in having a premium price, thus clarifying that the weight of importance of these variables depends on the specific targeted segment. 
In summary, tangible attributes tend to remain a solid baseline in determining the premium price to apply to tourism and hospitality services. They may be used to capture specific target in the old-fashioned traditional strategic dimension but they can also be applied in its tactical dimension, offering a tangible incremental attribute depending on service availability.

Hypothesis 1 (H1). Tangible attributes, in terms of the physical characteristics of the product offered, have the strongest role to determine price levels, and are used by operators both in a strategic and a tactical dimension.

Reputational variables. A used tool given to consumers to evaluate a tourism or hospitality service is represented by numerical ratings. This measure seems to be useful for other consumers at the time of making a reservation. Van Schaik and Ling (2009) report that in contexts where the consumer is in a goal oriented mode (e.g. making a hotel reservation) an easy info processing approach is preferred. This implies the reliance on easy to evaluate information, such that general category ratings (e.g., star ratings for hotels or online ratings) may have greater influence on the decision, compared with more detailed information. Ratings tend to be quite influential in product choice, because they provide shortcut means to assess and to evaluate a product (Chen, 2008; Tsang and Prendergast, 2009).

Reputation now assumes new forms with online reviews. In the past, reputations by experts were seen as more persuasive and complete (Herr et al., 1991; Bickart and Schindler, 2001). In this last decade there was the increase for not distorted information. The reviews of travelers were shown to count more than information provided by who offers tourism services (Gretzel and Yoo, 2008; D'Ambra and Wilson, 2004; Chen, 2008).

Despite fraudulent reviews from the same companies or competitors have been shown to pose a threat also for consumers' reviews (Hu et al., 2012), the role of consumer generated reviews is considered trustable and independent (Mauri and Minazzi, 2013), and it is gaining importance when compared with the traditional measures, such as the star rating of the hotel, which still remains important for overall evaluations (Zhang et al., 2011) but suffers from inconsistency for different regulations in different regions (Núñez-Serrano et al., 2014). Notably, this implies a shift from a pure strategic dimension present in standard catalogue prices, star rating, to a more tactical and fluid dimension, online review. On one hand, in fact, online reviews are still strategic because based on long-term attributes. On the other, they also provide a more tactical tool for improving reputation, as online reviews update constantly depending on the recent experiences of consumers.

Hypothesis 2 (H2). Compared to static catalogue prices, in dynamic pricing contexts online reviews gain relative importance over star rating.

Contextual variables. There are two different levels when assessing the impact of contextual variables. From a strategic dimension, the location of a tourism and hospitality service appears of paramount importance, 
either in terms of attractiveness and density of the area (Rigall-I Torrent and Fluvia', 2011) or in terms of competition (Balaguer and Pernias, 2013; Urtasun and Gutierrez, 2006). Since Chamberlin (1933), economic theory suggests a negative relation between the level of prices and the number of competitors. Theoretical and empirical evidence (Abrate et al., 2012; Balaguer and Pernias, 2013; Becerra et al., 2013; Gallego and $\mathrm{Hu}$; 2014) suggests that this traditional negative relationship holds in tourism and hospitality industries, especially with the diffusion of the Internet that simplified and made it almost inexpensive the way to gather information of competitive behavior.

From a tactical perspective, when location is fixed, contextual variables may still be fully exploited adopting appropriate dynamic pricing techniques. Abrate et al. (2012) show that in a dynamic context hotels decrease prices in real-time when the number of competitors with at least one available room decreases. Balaguer and Pernias (2013) enrich this finding, defining two levels of competition, and showing how the effect of competition is more intense during the weekend, with the presence of tourism travelers who are more flexible when choosing the place to stay at.

A contextual variable closely linked with competition and suitable for tactical dynamic price strategies is the booking time. Su (2007) and, more recently, Bachis and Piga (2011) show the importance of adjusting prices depending on booking time, in order to segment consumers according to their willingness to pay and their status (i.e. leisure or business customers). Generally, if the consumer that gives high value to the product buys at the last moment and the consumer that gives a relative lower value to the product is patient and willing to buy in advance the best strategy would be increasing pricing approaching the check-in. Recent applied research (Abrate et al., 2012; Bayoumi et al., 2013) stresses how booking time should be considered a crucial variable when it comes to implement dynamic pricing. There is a well-documented strand of research on the role of booking time in the airline industry (Piga et al., 2015; Bilotkach et al., 2010). Nonetheless, managing prices through booking time may be less effective in some tourism and hospitality services, because consumers can benefit from free cancellation, partially neutralizing the power of revenue management techniques adopted by operators. This phenomenon of offering free cancellation is rare in other industries, such as airlines and railways, increasing the value of an adequate dynamic pricing depending on booking time.

Hypothesis 3 (H3). The informative power of consumers' booking time, the option of free cancellation and the ongoing competitive scenario are embedded in dynamic pricing strategies.

All this leads to a fourth hypothesis. On one hand as highlighted by the Global Business Travel Association (GBTA, 2014), the adoption of dynamic pricing techniques is still not fully exploited and some operators are not benefiting from it. On the other, reputational issues may arise from the massive adoption of dynamic pricing based on contextual variables (Homburg et al., 2005). This latter concern might be more severe for high reputed operators, who might be more cautious in the adopting of such techniques to preserve their 
image. In other words, different behaviors could be observed depending on the different characteristics of the operators.

Hypothesis 4 (H4). Heterogeneous behavior in the use of dynamic pricing can be found across operators: due to image concerns, the use of tactical contextual variables tends to be lower for relatively high reputed operators.

\section{EMPIRICAL MODEL}

The conceptual framework can be tested using a hedonic price function approach. Hedonic price theory is usually traced back to a paper by Rosen (1974) but only Lancaster (1966) developed the idea of approaching goods and services as a bundle of objective attributes rather than homogeneous entities. This model assumes that the price of a composite product is the sum of the implicit values of each attribute that composes the product.

Coherently with this and the developed conceptual framework, the hedonic price function can be specified as follows:

$P=f(T, R, C)$

where tangible (T), reputational (R) and contextual (C) attributes can explain both the strategic and tactical dimension of price levels. It has to be noted that the function proposed here is not strictly hedonic as per Rosen (1974), considering that it accounts for contextual attributes, such as the number of competitors, which belong to competition theory. While the literature including market power variables in hedonic pricing models is still limited, theoretical support can be found in Ronnen (1991) and Harding et al. (2003), with applications in agriculture (Cotteleer et al., 2008) and tourism (Aguiló et al., 2003). Specifically, Ronnen (1991) portrays that hedonic prices fall due to a more intense price competition and Cotteleer et al. (2008) add that ignoring local market power may lead to an omitted variable bias on the estimated shadow prices in hedonic pricing models.

Although hospitality and tourism markets are appropriate as the object of hedonic research (Andersson, 2010), the models used are generally static, meaning that they give a single price for every observation (e.g., Israeli, 2002; Thrane, 2005), at most discriminating between high and low seasonality (White and Mulligan, 2002; Abrate et al., 2011). Only recently the literature has recognized the importance of accounting for the tactical determinants of price level, introducing a dynamic approach in the hedonic formulation (Alegre and Sard, 2015).

This paper provides a specific application in the field of the hospitality industry. This industry offers some favorable conditions such as easy access to price data through a unique search engine and standardized 
online rating systems, diffusion of dynamic price techniques, and a high number of competitors. This allows eliciting and isolating the impact of each factor.

The database consists of both catalogue price data (i.e. the long-term price positioning strategy of each hotel often used in the hedonic price literature) retrieved from the Milan Chamber of Commerce and real ongoing prices, collected from the website booking.com, one of the most used online engines to book a hotel.

The study samples a homogeneous geographical area in order to provide a better focus on the main goal of the paper: the study of price determinants at the tactical level. In particular, the selection covers the subsample of the historical center of Milan, with all the 57 hotels present at that time in booking.com. We chose 16 different check-in dates in October 2012, equally divided between intra-week and weekend. The month of October was selected to avoid contaminations of bank holidays on the attractiveness of a particular date. We gathered price information about these specific check-in days starting from July 2012, to detect as much as possible eventual variations in prices and other (tactical) attributes. In particular, the process of booking was simulated 26 different times in advance for every single of the 16 different check-in dates, always collecting the cheapest price of a single room, if available.

The final database consists of a total of 23.712 potential price observations: 57 hotels x 16 check-in dates $\mathrm{x}$ 26 booking times (in detail, the rates were first collected by simulating the booking process 90 days in advance, and then respectively $85,80,75,70,65,60,55,50,45,40,35,30,27,24,21,18,15,12,9,6,5,4$, 3, 2, 1 days from the check-in date). Nonetheless, the final number of available observations is 21.596 , as when retrieving the data in some of the simulated booking times hotels did not have any available room for a specific check-in date.

For what concerns price determinants, the following data are available.

- Hotel and room tangible attributes (T) are represented by the presence (yes or no) of a Spa and wellness center, the room dimension, the presence of a balcony, the total number of rooms of the establishment, the presence of a congress center and the presence of free internet in the room.

- Reputation (R) is represented both by a traditional measure such the star rating, and by the average online rating given by visitors (in a 1-10 scale).

- The set of contextual variables (C) that are supposed to be used by hotels to optimize dynamic price variations include time factors, the free cancellation option and the competitive presence. Time factors account for i) the booking time (simulated through the 26 different queries prior to check-in), ii) a dummy variable controlling for working days vs. weekend days and iii) the average daily hotel occupancy in the center of Milan for the investigated dates, retrieved from STR Share Center (an organization specialized in hotel data storage for academia and business). The competitive presence is operationalized with the number of competitors with at least one available room for the 
investigated night and their prices in real time. In particular, two measures of the number of competitors were retrieved: close competitors, defined as the number of hotels available within the same city area (that is, the center of Milan), and other competitors available, extending the geographical area to the whole metropolitan area of Milan. Then, a price index was constructed by dividing average prices charged in real time by close competitors (with available rooms) with respect to their catalogue prices.

Table 1. Variable taxonomy.

\begin{tabular}{|c|c|c|c|c|c|c|c|}
\hline \multirow{2}{*}{ Type of variable } & \multirow{2}{*}{ Variable } & \multirow{2}{*}{ Strategic } & \multirow{2}{*}{ Tactical } & \multirow{2}{*}{ Average } & \multicolumn{3}{|c|}{ Standard deviation } \\
\hline & & & & & Overall & Between & Within \\
\hline \multirow{2}{*}{$\begin{array}{l}\text { Price } \\
\text { (dependent } \\
\text { variable) }\end{array}$} & Catalogue price, $€$ & $\bar{X}$ & & 379.32 & 248.17 & 250.37 & 0 \\
\hline & $\begin{array}{l}\text { Real price charged (booking.com), } \\
€\end{array}$ & $\mathrm{X}$ & $\mathrm{X}$ & 245.18 & 159.84 & 144.82 & 66.04 \\
\hline \multirow{6}{*}{$\begin{array}{l}\text { Tangible } \\
\text { Attributes }\end{array}$} & Spa $($ yes $=1 ;$ no $=0)$ & $\mathrm{X}$ & & 0.15 & 0.36 & 0.36 & 0 \\
\hline & Squared meters & $\mathrm{X}$ & $\mathrm{X}$ & 19.15 & 8.02 & 7.30 & 3.15 \\
\hline & Balcony $($ yes $=1 ;$ no= $=0$ ) & $\mathrm{X}$ & $\mathrm{X}$ & 0.06 & 0.23 & 0.19 & 0.13 \\
\hline & Congress center $($ yes $=1 ;$ no $=0)$ & $\mathrm{X}$ & & 0.63 & 0.48 & 0.48 & 0 \\
\hline & Number of rooms & $\mathrm{X}$ & & 81.33 & 67.42 & 68.02 & 0 \\
\hline & Free internet $(\mathrm{yes}=1 ; \mathrm{no}=0)$ & $X$ & & 0.60 & 0.49 & 0.49 & 0 \\
\hline \multirow{2}{*}{$\begin{array}{l}\text { Reputational } \\
\text { attributes }\end{array}$} & Star Rating & $\mathrm{X}$ & & 3.96 & 0.67 & 0.68 & 0 \\
\hline & Online Reviews & $\mathrm{X}$ & $\mathrm{X}$ & 8.10 & 0.72 & 0.74 & 0.05 \\
\hline \multirow{7}{*}{$\begin{array}{l}\text { Contextual } \\
\text { Attributes }\end{array}$} & Booking time & & $\mathrm{X}$ & 35.65 & 28.36 & 0 & 28.36 \\
\hline & Weekend $($ yes $=1 ;$ no $=0)$ & & $X$ & 0.50 & 0.50 & 0 & 0.50 \\
\hline & Average occupancy (per cent) & & $\mathrm{X}$ & 85.01 & 4.32 & 0 & 4.32 \\
\hline & Free cancellation $($ yes $=1 ;$ no $=0)$ & & $\mathrm{X}$ & 0.53 & 0.50 & 0.42 & 0.28 \\
\hline & $\begin{array}{l}\text { Number of close competitors with } \\
\text { available rooms }\end{array}$ & & $\mathrm{X}$ & 53.99 & 5.41 & 0 & 5.41 \\
\hline & $\begin{array}{l}\text { Number of other competitors with } \\
\text { available rooms }\end{array}$ & & $\mathrm{X}$ & 227.37 & 13.30 & 0.02 & 13.30 \\
\hline & Competitors' price index & & $\mathrm{X}$ & 0.65 & 0.10 & 0.06 & 0.08 \\
\hline
\end{tabular}

The standard deviation is expressed taking into account of the panel dimension of the database (between-hotel and within-hotel standard deviation).

Table 1 presents the taxonomy for the available data, specifying whether each variable has a strategic and/or tactical dimension. Moreover, the table shows the descriptive statistics of the variables, including in particular details concerning the cross-section variability (between hotel) as well as the time variability (within-hotel). The distinction between cross-section and time variability stands at the core of our empirical strategy. The double nature of pricing decision, i.e. strategic and tactical, has long been recognized by the marketing literature (Rao, 1984). Empirically, the hedonic literature has provided insights mainly for longterm pricing strategy (Thrane, 2007; Chen and Rothschild, 2010), though falling short in explaining dynamic pricing decisions in the short-run. The peculiarity of this study, as explained also in the theoretical framework, lies in the attempt of capturing the dynamic dimension of attributes that are traditionally considered, in the hedonic pricing literature, in their static dimension. For this reason, cross-sectional price variability, which mostly reflects long-term structural choices of different hotels, is interpreted as the 
strategic dimension of pricing decisions. Conversely, within-hotel price variability depends on the way hotels adjust their prices in the short-run, and is interpreted as the tactical price dimension.

By briefly analyzing the descriptive statistics presented in Table 1, it is worth mentioning that the average real price charged in online channels is way below the catalogue price, since the latter represents for each hotel the legal upward threshold (in case of a standard room). Moreover, some tangible attributes (namely, square meters and balcony) do vary in the time dimension, reflecting the way a hotel adjusts its offer, and in particular the offered attributes of its cheapest room option.

We compare 4 alternative models, with the aim of disentangling the contribution of each group of variable to the price formation.

MODEL 1: $\ln \left(\mathrm{P}_{\mathrm{c} a t}\right)=\mathrm{f}(\mathrm{T}, \mathrm{R})+\varepsilon_{i}$

MODEL 2: $\ln \left(\right.$ Pmed $\left._{i}\right)=\mathrm{f}(\mathrm{T}, \mathrm{R})+\varepsilon_{i}$

MODEL 3: $\ln \left(\right.$ Preal $\left._{i t}\right)=\mathrm{f}(\mathrm{T}, \mathrm{R}, \mathrm{C})+u_{i}+\varepsilon_{i t}$

MODEL 4: $\ln \left(\right.$ Preal $\left._{t}\right)=\mathrm{f}(\mathrm{T}, \mathrm{R}, \mathrm{C})+\varepsilon_{t}$ (estimated for each hotel $i=1$ to 57$)$

In Model 1, the dependent variable is represented by the standard catalogue price (Pcat) of the basic room. Since for each hotel we have a unique price observation, tactical variables are not relevant. Similarly, in Model 2, while considering all the real prices charged during the observed period, the dependent variable is computed as the median value ( $\mathrm{P} m e d$ ) applied by each specific hotel. Thus, again, we have a unique price observation for each hotel, i.e., dynamic variability is removed. Model 3 exploits the full potential of the panel dataset and uses a random-effect regression analysis with clustered errors to explain both cross-section and time variability of real prices (Preal). These prices are observed for any hotel $i$ and at any time $t$. Thus, in this case, also contextual variables come into play. The term $u_{i}$ represents the individual specific error of the random regression model. A Sargan-Hansen test of overidentifying restrictions does not reject the appropriateness of the random effect versus the fixed effect model $(p=0.16)$.

Finally, the analysis is replicated by means of separate OLS regressions for each hotel $i$ (Model 4), recognizing that the determinants of dynamic price variability may be heterogeneous across hotels.

For each model, the study investigates which are the most relevant variables in determining the hotel pricing strategies. One convenient measure is given by the Shapley value (Shapley, 1953), which has been developed in cooperative game theory to compute the distribution of the total outcome obtained by a coalition of players starting with the contribution of each player in the coalition. This concept can be extended to estimate the contribution of a single variable to a statistical indicator of goodness-of-fit of the adopted model, such as the R-squared (Huettner and Sunder, 2012; Shorrocks, 2013). More formally, given a 
full regression model with $K$ explanatory variables $\left(x_{1}, x_{2}, \ldots, x_{K}\right)$, computing the contribution of each variable requires the estimation of all possible sub-models (considering all $K$ ! permutations of regressors):

$$
R_{j}^{2}=\frac{1}{K !} \sum_{\theta} R^{2}\left(f\left(x_{j}^{\theta}, x_{j}\right)\right)-R^{2}\left(f\left(x_{j}^{\theta}\right)\right)
$$

where $\theta$ defines any of the $K$ ! variable orderings.

The marginal contribution to R-squared is given by the R-squared of the model that includes $x_{j}$ and all regressors preceding $x_{j}$ in that particular order $\left(x_{j}^{\theta}\right)$ minus the R-squared of the model that does not includes $x_{j}$. Thus, the Shapley value is the variable's average marginal contribution to R-squared over all possible orderings.

Following the same principles, the Owen value is an extension that allows focusing on the contribution of apriori defined groups of variables rather than single variables (Owen, 1977), reducing the number of possible permutations and the computational complexity. This approach appears particularly useful in our hedonic pricing model, where the interest is on the relative importance of certain group of variables (i.e., tangible, reputational and contextual).

\section{RESULTS AND DISCUSSION}

The empirical results are presented and discussed in the light of the conceptual framework above defined. Table 2 shows the estimated coefficients of Models 1-3, as well as some goodness-of-fit and predictive power measures. The overall R-squared in Model 1 and 2 is close to the between R-squared in Model 3, indicating that the cross-sectional fit does not change. The additional explanatory power of Model 3 is expressed by the within R-squared (0.245). Besides the R-squared, the Median Absolute Percentage Error (MdAPE) complements the analysis comparing the predictive power of the models (Armstrong, 2012). The ability to predict actual pricing behavior increases, as expected, moving from Model 1 and 2 to Model 3. Unsurprisingly, predictions of Model 1 are far from real prices because catalogue prices only represent a hypothetical maximum reference. The MdAPE lowers to 16\% in Model 2 and shows an additional decrease to a level below $10 \%$ in Model 3, thanks to the explicit consideration of the within-hotel variability.

The impact of tangible attributes is not significant in Models 1 and 2. This might be due to a positive correlation between tangible attributes and star ratings (Yacouel and Fleischer, 2012), and to the limited number of cross-section observations. Nonetheless, when employing jointly cross-section and time variability of real prices (Model 3), the impact of room dimension, spa and balcony is significant and shows the expected sign. These controversial findings cast an initial doubt on the importance of tangible attributes, at least in its strategic dimension. 
Table 2. Results of regression Models 1-3.

\begin{tabular}{|c|c|c|c|}
\hline & Model 1 & Model 2 & Model 3 \\
\hline Variables & $\begin{array}{c}\text { Catalogue } \\
\text { price }\end{array}$ & $\begin{array}{c}\text { Median } \\
\text { of real prices }\end{array}$ & $\begin{array}{l}\text { Real } \\
\text { Price } \\
\end{array}$ \\
\hline Constant & $\begin{array}{c}3.5942 * * * \\
(0.3841)\end{array}$ & $\begin{array}{c}2.5833 * * * \\
(0.3488)\end{array}$ & $\begin{array}{c}1.7137 \\
(1.1894)\end{array}$ \\
\hline 4 star (dummy) & $\begin{array}{c}0.3560 * * * \\
(0.0923)\end{array}$ & $\begin{array}{c}0.1709 * * \\
(0.0841)\end{array}$ & $\begin{array}{c}0.1651 \\
(0.1118)\end{array}$ \\
\hline 5 star (dummy) & $\begin{array}{c}1.0502 * * * \\
(0.1452)\end{array}$ & $\begin{array}{c}0.7010^{* * *} \\
(0.1263)\end{array}$ & $\begin{array}{c}0.5252 * * * \\
(0.1554)\end{array}$ \\
\hline Balcony (dummy) & $\begin{array}{c}0.1058 \\
(0.2119)\end{array}$ & $\begin{array}{c}0.2237 \\
(0.1954)\end{array}$ & $\begin{array}{c}0.1313 * * * \\
(0.0388)\end{array}$ \\
\hline Room dimension & $\begin{array}{l}0.0131 * \\
(0.0073)\end{array}$ & $\begin{array}{l}0.0117 * \\
(0.0068)\end{array}$ & $\begin{array}{c}0.0233 * * * \\
(0.0027)\end{array}$ \\
\hline Spa (dummy) & $\begin{array}{l}-0.0502 \\
(0.1153)\end{array}$ & $\begin{array}{c}0.1285 \\
(0.1082)\end{array}$ & $\begin{array}{c}0.1514 * * * \\
(0.0402)\end{array}$ \\
\hline Congress facilities & $\begin{array}{c}0.0180 \\
(0.0804)\end{array}$ & $\begin{array}{c}0.0057 \\
(0.0745)\end{array}$ & $\begin{array}{c}0.0092 \\
(0.0675)\end{array}$ \\
\hline Number of rooms & $\begin{array}{l}-0.0001 \\
(0.0005)\end{array}$ & $\begin{array}{l}-0.0003 \\
(0.0005)\end{array}$ & $\begin{array}{l}-0.0001 \\
(0.0004)\end{array}$ \\
\hline Free internet & $\begin{array}{l}-0.0749 \\
(0.0711)\end{array}$ & $\begin{array}{l}-0.0197 \\
(0.0659)\end{array}$ & $\begin{array}{l}-0.0352 \\
(0.0673)\end{array}$ \\
\hline Online reputation & $\begin{array}{c}0.1964 * * * \\
(0.0526)\end{array}$ & $\begin{array}{c}0.2790 * * * \\
(0.0473)\end{array}$ & $\begin{array}{c}0.3626 * * \\
(0.1676)\end{array}$ \\
\hline Booking time & & & $\begin{array}{l}0.0014 * \\
(0.0008)\end{array}$ \\
\hline Booking time ${ }^{\wedge} 2$ & & & $\begin{array}{l}-0.0000 \\
(0.0000)\end{array}$ \\
\hline Weekend & & & $\begin{array}{l}-0.0088 \\
(0.0147)\end{array}$ \\
\hline Average Occupancy & & & $\begin{array}{c}0.0044 * * * \\
(0.0010)\end{array}$ \\
\hline Free Cancellation (dummy) & & & $\begin{array}{c}0.0884 * * * \\
(0.0349)\end{array}$ \\
\hline Number of close competitors & & & $\begin{array}{l}-0.0034 * \\
(0.0018)\end{array}$ \\
\hline Number of other competitors & & & $\begin{array}{l}-0.0004 \\
(0.0004)\end{array}$ \\
\hline In (competitors' price index) & & & $\begin{array}{l}0.320 * * * \\
(0.0704)\end{array}$ \\
\hline Total number of observations & 57 & 57 & 21596 \\
\hline Number of groups (hotel) & 57 & 57 & 57 \\
\hline Observation $\mathrm{x}$ group & 1 & 1 & $\min 238 ; \max 416$ \\
\hline R-squared (between) & & & 0.846 \\
\hline R-squared (within) & & & 0.245 \\
\hline R-squared (overall) & 0.846 & 0.849 & 0.749 \\
\hline MdAPE & $56.53 \%$ & $16.05 \%$ & $9.76 \%$ \\
\hline
\end{tabular}

Standard errors in brackets. $* * * p<0.01 ; * * p<0.05 ; * p<0.10$

Model 1 and 2: OLS estimates. Model 3: Unbalanced panel data random effect estimates with clustered standard errors. MdAPE is the Median Absolute Percentage Error when using the estimates to predict real prices. 
The impact of reputational attributes is significant in all models. While the impact of online rating is larger on the real price charged $(0.3626, p<0.01)$ rather than the catalogue price $(0.1964, p<0.01)$, the contrary happens for star rating dummies, providing a first support to $H 2$. Increasing the value of online reviews allows improving price positioning, and seems to represent a viable alternative to the engagement of an expensive process aimed at upgrading the star rating.

As for the contextual variables, the positive coefficient associated to the booking time $(0.0014, p<0.10)$ indicates a slightly decreasing trend of prices when approaching the check-in date providing evidence of last minute strategies. While there is no evidence of a weekend price-shift, the general level of demand, measured by the average occupancy rate in the center of Milan for the collected dates, exerts a significant pressure on the price level: a one percent increase in the average occupancy would lead, on average, to a $0.44 \%$ price increase.

Results also show a significant positive impact of the free cancellation option in the price determination. This result can be explained as the additional charge for increasing customer flexibility. Indeed, the diffusion of discounted offers without free cancellation represents a viable way for operators to be protected from possible strategic consumer reaction to revenue management practices. A shrinkage in the number of close competitors increases price significantly $(-0.0034, p<0.10)$, while other competitors do not have a significant effect. Finally, moving to the tactical reaction to the competitors' price index, each $1 \%$ average price increase by competitors induces a $0.32 \%$ price reaction. On the whole, when competitors with at least one available room either decrease in number or increase their proposed price, the remaining operators gain potential market power. Exploiting this potential with appropriate revenue management tools represents an important opportunity for players operating in these markets. These results support the hypothesis that operators consider the informative power of consumers' booking time, the option of free cancellation and the ongoing competitive scenario when designing dynamic pricing strategies (H3).

Table 3 presents the correlations of the variables used in the regression models to spot potential problems of multicollinearity. Apart from a relatively high correlation between the number of close competitors and the number of other competitors $(r=0.73, p<0.01)$, the level of correlation between all the variables is always well below 0.7 thus not showing serious multicollinearity issues. 
Table 3. Pearson correlation.

\begin{tabular}{|c|c|c|c|c|c|c|c|c|c|c|c|c|c|c|c|c|}
\hline & 4 star & 5 star & Balcony & Room $m^{2}$ & Spa & Congress & N. of rooms & Free Internet & Online rep. & Booking time & Weekend & Occupancy & Free cancel. & Close comp. & Other comp. & Price Index \\
\hline 4 star & 1 & & & & & & & & & & & & & & & \\
\hline 5 star & $-0.56^{*}$ & 1 & & & & & & & & & & & & & & \\
\hline Balcony & $-0.20^{*}$ & $0.35^{*}$ & 1 & & & & & & & & & & & & & \\
\hline Room m ${ }^{2}$ & $-0.22^{*}$ & $0.65^{*}$ & $0.46^{*}$ & 1 & & & & & & & & & & & & \\
\hline Spa & $-0.26^{*}$ & $0.55^{*}$ & $0.13^{*}$ & $0.53^{*}$ & 1 & & & & & & & & & & & \\
\hline Congress & $-0.03^{*}$ & $0.31^{*}$ & $0.07^{*}$ & $0.24^{*}$ & $0.31^{*}$ & 1 & & & & & & & & & & \\
\hline N. of rooms & $0.10^{*}$ & $0.09^{*}$ & $0.22^{*}$ & $0.08^{*}$ & $-0.05^{*}$ & $0.36^{*}$ & 1 & & & & & & & & & \\
\hline Free Internet & $0.16^{*}$ & $0.07^{*}$ & $0.13^{*}$ & $0.13^{*}$ & 0.01 & $-0.18^{*}$ & 0.01 & 1 & & & & & & & & \\
\hline Online rep. & $0.08^{*}$ & $0.26^{*}$ & $0.26^{*}$ & $0.46^{*}$ & $0.28^{*}$ & $0.20^{*}$ & $-0.06^{*}$ & $0.17^{*}$ & 1 & & & & & & & \\
\hline Booking time & 0.00 & 0.00 & $-0.05^{*}$ & $-0.06^{*}$ & -0.01 & 0.00 & 0.00 & 0.01 & 0.00 & 1 & & & & & & \\
\hline Weekend & 0.00 & 0.00 & $0.03 *$ & $0.19 *$ & 0.01 & 0.00 & 0.00 & 0.00 & 0.00 & 0.00 & 1 & & & & & \\
\hline Occupancy & 0.00 & 0.00 & 0.00 & $0.02^{*}$ & 0.01 & 0.00 & 0.00 & 0.00 & 0.00 & 0.00 & $0.09^{*}$ & 1 & & & & \\
\hline Free Cancel. & -0.12 & $0.05^{*}$ & $0.13^{*}$ & 0.01 & -0.01 & $-0.10^{*}$ & -0.13 & $0.17^{*}$ & $-0.02^{*}$ & $0.06^{*}$ & $-0.04 *$ & 0.00 & 1 & & & \\
\hline Close Comp. & -0.00 & 0.00 & $-0.04 *$ & $-0.11^{*}$ & $-0.02^{*}$ & 0.00 & 0.00 & 0.01 & -0.01 & $0.56^{*}$ & $-0.31 *$ & $-0.27^{*}$ & $0.07 *$ & 1 & & \\
\hline Other Comp. & 0.00 & 0.00 & $-0.04 *$ & $-0.07 *$ & $-0.01 *$ & -0.00 & 0.00 & 0.01 & 0.00 & $0.38^{*}$ & $-0.14 *$ & $-0.31 *$ & $0.07^{*}$ & $0.73^{*}$ & 1 & \\
\hline Price Index & $-0.20^{*}$ & $-0.20^{*}$ & $-0.11^{*}$ & $-0.21^{*}$ & $-0.24 *$ & $-0.22^{*}$ & $-0.12^{*}$ & $-0.16^{*}$ & $-0.22^{*}$ & $0.05^{*}$ & $0.36^{*}$ & $0.29^{*}$ & $0.03 *$ & $-0.22 *$ & $-0.22^{*}$ & 1 \\
\hline
\end{tabular}

Pearson correlation of the variables used in the regression models of Table 2 .

$* p<0.01$ 
Table 4. Relative weight of tangible, reputational and contextual factors.

\begin{tabular}{|c|c|c|c|c|c|c|}
\hline & & \multirow{2}{*}{\multicolumn{3}{|c|}{ Cross-Section (Strategic dimension) }} & & \\
\hline & & & & & \multicolumn{2}{|c|}{ Time (Tactical dimension) } \\
\hline & & Model 1 & Model 2 & $\begin{array}{c}\text { Model 3 } \\
\text { (between) } \\
\end{array}$ & $\begin{array}{l}\text { Model 3 } \\
\text { (within) } \\
\end{array}$ & $\begin{array}{c}\text { Model } 4 \\
\text { (average values) }\end{array}$ \\
\hline & & $R^{2}=0.846$ & $R^{2}=0.849$ & $R^{2}=0.846$ & $R^{2}=0.245$ & $R^{2}=0.575$ \\
\hline Tangible & Physical attributes & $34.0 \%$ & $34.1 \%$ & $35.6 \%$ & $50.9 \%$ & $37.1 \%$ \\
\hline \multirow[t]{2}{*}{ Reputation } & Traditional (Stars) & $49.1 \%$ & $38.0 \%$ & $38.7 \%$ & $0.0 \%$ & $0.0 \%$ \\
\hline & Online & $16.9 \%$ & $27.9 \%$ & $25.7 \%$ & $4.0 \%$ & $3.3 \%$ \\
\hline \multirow{3}{*}{ Contextual } & Time & & & & $17.1 \%$ & $33.4 \%$ \\
\hline & Free cancellation & & & & $4.9 \%$ & $7.3 \%$ \\
\hline & Competition & & & & $23.1 \%$ & $18.9 \%$ \\
\hline \multicolumn{2}{|c|}{ Total explained variance } & $100 \%$ & $100 \%$ & $100 \%$ & $100 \%$ & $100 \%$ \\
\hline
\end{tabular}

The R-squared of each model in Table 2 is decomposed according to its determinants, by means of Shapley-Owen technique. Thus, each value represents the share of $R$-squared explained by each group of factors.

The Shapley-Owen decomposition of R-squared values, reported in Table 4, allows measuring the relative weight of each group of variables, tangible, reputational, and contextual, in terms of explaining price levels. At the strategic level, the contribution of tangible attributes is substantially relevant and consistent across models, ranging from $34 \%$ to $36 \%$, somehow in contradiction with the findings from Table 2 . This asymmetry confirms the conjecture that a limited number of observations and the correlation between star ratings and tangible variables are driving the non-significant results on tangible coefficients in Models 1 and 2. The Shapley analysis of the partial contributions to R-squared (Table 4) allows disentangling the relative importance of tangibles and star rating, showing that both are relevant in terms of R-squared contribution. This result provides only partial support to $H 1$, because reputational variables prove to be the most important factor, at least in the strategic dimension. Specifically, in Model 1 star rating explains almost 50\% of catalogue price variability. In Model 2 and 3, which account for real observed prices, the star rating contribution decrease to $38 \%$ while there is an increase of importance of online rating in explaining the cross-section variability (in line with $H 2$ ).

As to the tactical level, in Model 3 the most relevant contribution comes from tangible (51\%). This means that most price variations for a single hotel are driven by different types of rooms that are available at different times. However, contextual variables are important as well, and here a major role is played by time (17\%) and competition (23\%). One might observe that within-group R-squared is not very high (0.245), especially if compared to the capability of the model to describe cross-section variability (0.846). Though dynamic behavior is certainly more difficult to be modeled without knowing hoteliers' private information (e.g., in particular, availability of rooms at a certain moment), dynamic tactics might be very different across hotels, thus one reason for the low R-squared might be due to the imposition (in Model 3) of a uniform behavior. This limitation can be solved by running separate regressions for each hotel (Model 4). As shown in the last column of Table 4, on average, the R-squared of each regression is 0.575 (and MdAPE drops to 6.7 percent), with a great improvement with respect to the general within-group R-squared above, and with a much higher importance of time factors (more than 33\%). A viable alternative to running separate 
regressions would have been estimating a single price equation enriching Model 3 by including interactions between hotels and covariates, and thus allowing for each hotel a specific parameter associated to each explanatory variable. This approach would lead to similar results: the within-group R-squared would increase to 0.583 , with tangible attributes explaining $31.3 \%$ of price variability, online reputation $3.6 \%$ and contextual variables the remaining $65.1 \%$ (time $36.3 \%$, competition $19.9 \%$ and free cancellation $8.9 \%$ ). However, the separate regression approach is more feasible in this specific case, as it allows measuring for each hotel the Shapley values to be included in the cluster analysis.

In sum, while the results on strategic dimension provide full support to $H 2$ and only partial support to $H 1$, the analysis of within-hotel variability and its determinants allows supporting the conceptual framework, in its hypotheses $\mathrm{HI}$ and $\mathrm{H3}$, as well as an initial support to the presence of heterogeneous behavior in dynamic pricing tactics $(H 4)$.

With the goal of providing further testing for $H 4$, the study identifies heterogeneous groups through hierarchical cluster analysis (HCA). This is a statistical method for finding groups or subtypes of related cases in multivariate data (for review, see Bartholomew et al., 2011). Input variables for the HCA were the Shapley's contributions of the tangible, reputational and contextual components, as in the fifth column of Table 4, for each of the 57 hotels. The approach allows creating a number of centroids and assigning all the number of observations to one of the centroids. We chose a solution based on the lowest average weight of evidence (AWE), because this metric combines information on model fit and information on classification errors. The solution with the lowest AWE is characterized by two groups. The output of the analysis is presented in Figure 2 and complemented by Table 5.

\section{Figure 2. Hierarchical cluster analysis.}

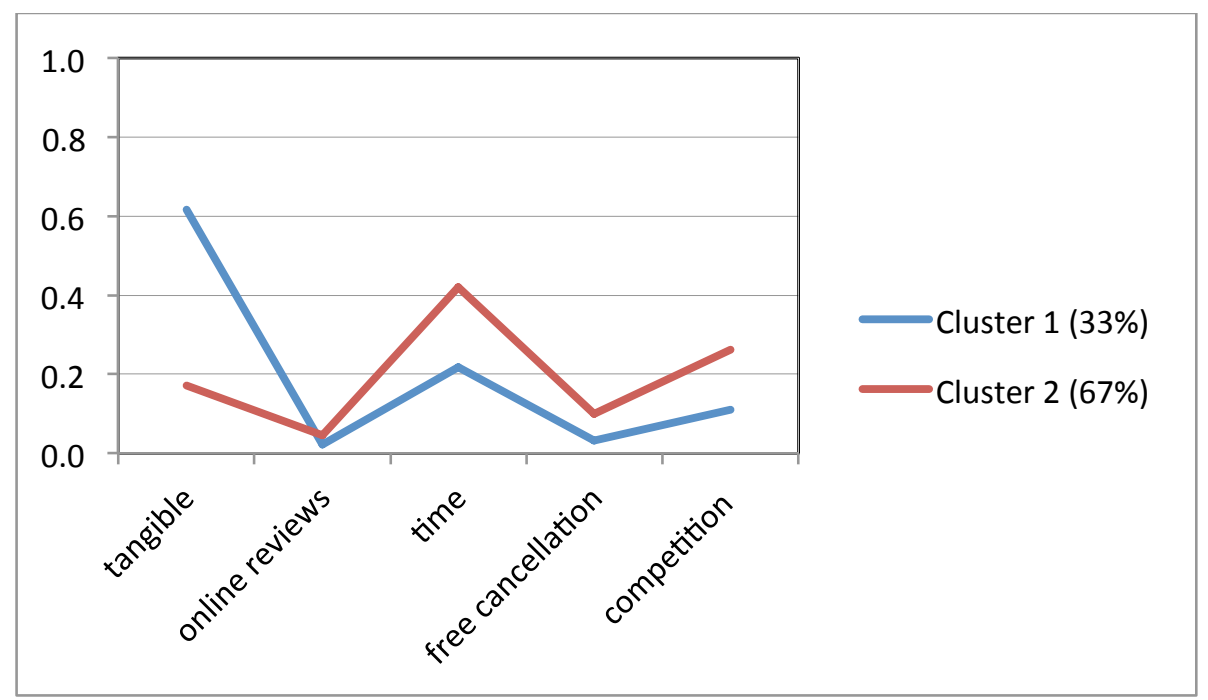

The input variables for the hierarchical cluster analysis are the Shapley's contributions of the tangible, reputational and contextual components for each of the 57 hotels in the database. Relative number of hotels per cluster are in parenthesis. 
Figure 2 shows the size of the groups and their profiling in terms of attributes. Of the 57 hotels, we can see that more than half belongs to Cluster 2 , where the price variability is almost entirely explained by tangibles. Interestingly, Cluster 1 exploits all the other sources of price variability, by scoring higher with respect to Cluster 2 in all the contextual dimensions: time, free cancellation and competition.

Table 5. Clusters' profiling.

\begin{tabular}{lccc}
\hline & Cluster 1 & Cluster 2 & Total \\
\hline Average price & 309.68 & 233.63 & 258.52 \\
\hline Dynamic price variability & 0.19 & 0.24 & 0.23 \\
\hline$\%$ of total number of hotels & $33 \%$ & $66 \%$ & $100 \%$ \\
\hline$\%$ of 3 stars & $28.6 \%$ & $71.4 \%$ & $100 \%$ \\
$\%$ of 4 stars & $29.0 \%$ & $71.0 \%$ & $100 \%$ \\
$\%$ of 5 stars & $50 \%$ & $50 \%$ & $100 \%$ \\
\hline
\end{tabular}

The dynamic price variability is the average within-hotel price variability, computed by means of coefficient of variation. The percentages present the distribution of observations in the clusters.

Table 5 looks at the characteristics of each cluster. Cluster 1 is composed in great part by 5 -star hotels with higher price levels and with a much more limited use of dynamic pricing, computed by means of coefficient of variation of prices $(\mathrm{CV}=0.19) .3$ and 4-star hotels mainly represent the smaller sample of hotels in Cluster 2. In this cluster there is a more intense use of dynamic pricing techniques $(\mathrm{CV}=0.24)$. In particular, a post hoc Tukey test confirms that Cluster 2 has a significantly higher CV than Cluster $1(p<0.05)$. This heterogeneous behavior between clusters, and in particular the more cautious approach to price variations of the high reputed hotels in Cluster 1, complements the support given to $H 4$.

Another way to test for heterogeneity in pricing behavior is reconsidering the panel regression analysis in Model 3, including interaction terms between explanatory variables and a-priori selected groups of hotels as additional regressors. In particular, the study tests the interaction between the contextual variables and two different ways of grouping the hotels: (i) the two groups from the cluster analysis and (ii) the groups of hotels by star category. Table 6 summarizes the results, reporting the coefficients only when the difference between groups is statistically significant. As expected, the impact on price of booking time, average occupancy, number of close competitors and the competitors' price index is more relevant in the hotels belonging to Cluster 2. On the contrary, only few interactions with star rating came out to be significant. Among those, it is worth mentioning how 3 Star hotels tend to raise prices during weekends and to look more to other competitors while 4 Star hotels seem to be the most influenced by the competitors' price index. 
Table 6. Impact on prices of contextual variable by group of hotels

\begin{tabular}{|c|c|c|c|c|}
\hline Variables & Cluster 1 vs. 2 & 3 Stars vs. 4 Stars & 3 Stars vs. 5 Stars & 4 Stars vs. 5 Stars \\
\hline Booking time & $(0.000 \text { vs. } 0.002)^{* * *}$ & & & \\
\hline Weekend & & $(0.122 \text { vs. }-0.017)^{* * *}$ & $(0.122 \text { vs. }-0.012)^{* * *}$ & \\
\hline Average Occupancy & $(0.002 \text { vs. } 0.006)^{* * *}$ & & & \\
\hline \multicolumn{5}{|l|}{ Free Cancellation } \\
\hline Number of close competitors & $(0.000 \text { vs. }-0.005)^{*}$ & & & \\
\hline Number of other competitors & & $(-0.003 \text { vs. } 0.000)^{* *}$ & $(-0.003 \text { vs. }-0.001)^{*}$ & \\
\hline In (competitors' price index) & $(0.150 \text { vs. } 0.387)^{* *}$ & $(-0.004 \text { vs. } 0.309)^{* *}$ & & $(0.309 \text { vs. } 0.057)^{* * *}$ \\
\hline
\end{tabular}

\section{CONCLUSIONS}

This study builds and empirically validates a new framework to better understand the dynamic pricing applications in the tourism and hospitality industries. Specifically, the paper shows how dynamic pricing is based on three groups of variables: tangible, reputational and contextual, with interplay between strategic and tactical dimension. With a methodological approach based on a dynamic hedonic price function, the study supports that tactical price decisions tend to be heavily influenced by the informational power of contextual variables, in particular by the amount of competitors in real-time. Also reputation by means of online customers' reviews, a more volatile variable when compared with traditional forms of reputation, plays an increasing role in price decisions. These results support the argument made by Narangajavana et al. (2014) on the complexity of mechanisms used by tourism companies to incorporate different perspectives in their pricing strategies.

Many managerial implications arise. First, the power of tangible attributes remains relevant, and may be also used as a tool to enrich the available tactical options for revenue managers. For example, a hotel with almost fully occupied standard rooms many days in advance with respect to the check-in date might decide to remove the availability of the room, letting for a certain period only the option to book premium rooms. The same mechanism can be applied in other related industries, where different levels of tangible attributes are present (e.g. seats in business vs. economy class in travel companies). Second, online reviews acquires increasing importance in the reputational arena, therefore additional effort should be made to satisfy and improve customers' experiences and expectations over time, encouraging and supporting loyal customers to leave thorough feedbacks. A plan of action to effectively implement this is presented by Sotiriadis and van Zyl, C. (2013): trained staff members should constantly monitor reviews and address feasible suggestions with the goal of improving customers' experience. Finally, operators should enhance the adoption of techniques to monitor competition, especially geographically close competitors. Some are already doing it successfully, others tend to follow or to maintain a more prudential approach. An interesting case in the empirical validation proposed is given by the group of 5-star hotels, whose price tactics seem only 
moderately influenced by contextual variables. A possible explanation for such finding is that adopting intense price variations just "following the crowd" (i.e. the competitors) might impact on their image, especially if such variations are not justified by a service upgrade in terms of tangible attributes.

The main limitation of the study is that it explores only one city in detail. In addition, the empirical part of the analysis makes use of the cheapest price offer for a single room. Future work can explain temporal price variance for otherwise the same product by excluding the cases where the product being offered was slightly different (e.g., free cancellation and upgrades) from one booking time to the other. Another interesting avenue for future research is the application of the Shapley method in a spatial setting.

Despite the focus is on the values of hotel characteristics to buyers of hotels without the need to model formally the supply side of the market (Vanslembrouck et al., 2005), costs might affect revenue management strategies. Finally, the way tangible, reputational and contextual variables interact with short-term and longterm profitability represents an interesting topic for future research. 


\section{REFERENCES}

Abrate, G., Capriello, A., Fraquelli, G. (2011). When quality signals talk: evidence from the Turin hotel industry. Tourism Management 32, 912-921.

Abrate, G., Fraquelli, G., Viglia, G. (2012). Dynamic pricing strategies: evidence from European hotels. International Journal of Hospitality Management 31(1), 160-168.

Aguiló, E., Alegre, J., Sard, M. (2003). Examining the market structure of the German and UK tour operating industries through an analysis of package holiday prices. Tourism Economics 9(3), 255-278.

Alegre, J., Sard, M. (2015). When demand drops and prices rise. Tourist packages in the Balearic Islands during the economic crisis. Tourism Management 46, 375-385.

Andersson, D. E. (2010). Hotel attributes and hedonic prices: an analysis of internet-based transactions in Singapore's market for hotel rooms. The Annals of Regional Science 44(2), 229-240.

Armstrong, J. S. (2012). Illusions in regression analysis. International Journal of Forecasting, 28, 689-694.

Bachis, E., Piga, C. A. (2011). Low-cost airlines and online price dispersion. International Journal of Industrial Organization 29(6), 655-667.

Balaguer, J., Pernías, J.C. (2013). Relationship between spatial agglomeration and hotel prices. Evidence from business and tourism consumers. Tourism Management 36, 391-400.

Bartholomew, D. J., Knott, M., Moustaki, I. (2011). Latent variable models and factor analysis: A unified approach (Vol. 904). John Wiley \& Sons.

Bayoumi, A. E. M., Saleh, M., Atiya, A. F., Aziz, H. A. (2013). Dynamic pricing for hotel revenue management using price multipliers. Journal of Revenue \& Pricing Management 12(3), 271-285.

Becerra, M., Santaló, J., Silva, R. (2013). Being better vs. being different: Differentiation, competition, and pricing strategies in the Spanish hotel industry. Tourism Management 34, 71-79.

Bickart, B., Schindler, R. M. (2001). Internet forums as influential sources of consumer information. Journal of interactive marketing 15(3), 31-40.

Bilotkach, V., Gorodnichenko, Y., Talavera, O. (2010). Are airlines' price-setting strategies different? Journal of Air Transport Management 16(1), 1-6.

Bull, A. O. (2006). 5 Industrial economics and pricing issues within tourism enterprises and markets. In International handbook on the economics of tourism, 138-154. 
Chen, Y. F. (2008). Herd behavior in purchasing books online. Computers in Human Behavior 24(5), 19771992.

Chamberlin, E. H. (1933). The Theory of Monopolistic Competition. Cambridge, MA, Harvard University Press.

Chen, C. F., Rothschild, R. (2010). An application of hedonic pricing analysis to the case of hotel rooms in Taipei. Tourism Economics 16(3), 685-694.

Coenders, G., Espinet, J., Saez, M. (2003). Predicting random level and seasonality of hotel prices: a latent growth curve approach. Tourism Analysis 8(1), 15-31.

Cotteleer, G., Gardebroek, C., Luijt, J. (2008). Market power in a GIS-based hedonic price model of local farmland markets. Land Economics 84(4), 573-592.

Cross, R. G. (1997). Launching the revenue rocket: how revenue management can work for your business. The Cornell Hotel and Restaurant Administration Quarterly 38(2), 32-43.

D'Ambra, J., Wilson C. (2004). Use of the World Wide Web for international travel: integrating the construct of uncertainty in information seeking and the task-technology fit (TTF) model. Journal of the American Society for Information Science and Technology 55(8), 731-742.

Dixit, A., Braunsberger, K., Zinkhan, G., Pan, Y. (2005). Information technology-enhanced pricing strategies: managerial and public policy implications. Journal of Business Research 58(9), 1169-1177.

Dixit, A., Whipple, T., Zinkhan, G., Gailey, E. (2008). A taxonomy of information technology-enhanced pricing strategies. Journal of Business Research 61(4), 275-283.

Espinet, J. M., Saez, M., Coenders, G., \& Fluvià, M. (2003). Effect on prices of the attributes of holiday hotels: a hedonic prices approach. Tourism Economics 9(2), 165-177.

Gallego, G., Hu, M. (2014). Dynamic pricing of perishable assets under competition. Management Science 60(5), 1241-1259.

Garbarino, E., Maxwell, S. (2010). Consumer response to norm-breaking pricing events in e-commerce. Journal of Business Research 63(9), 1066-1072.

GBTA (2014). Dynamic Hotel Pricing - Has Its Time Come?, available at "http://www.gbta.org/Education/Pages/14d11002.aspx"

Gretzel, U., Yoo, K. H. (2008). Use and impact of online travel reviews. In O'Connor, P., Hopken, W., Gretzel, U. (eds.), Information and Communication Technologies in Tourism, pp. 35-46, Springer, Wien/New York. 
Grönroos, C., Ojasalo, K. (2004). Service productivity: towards a conceptualization of the transformation of inputs into economic results in services. Journal of Business Research 57(4), 414-423.

Harding, J. P., Rosenthal, S. S., Sirmans, C. F. (2003). Estimating bargaining power in the market for existing homes. Review of Economics and Statistics, 85(1), 178-188.

Herr, P. M., Kardes, F. R., Kim, J. (1991). Effects of word-of-mouth and product-attribute information on persuasion: An accessibility-diagnosticity perspective. Journal of Consumer Research 17(4), 454-462.

Homburg, C., Koschate, N., Hoyer, W. D. (2005). Do satisfied consumers really pay more? A study of the relationship between consumer satisfaction and willingness to pay. Journal of Marketing 69(2), 84-96.

Hu, N., Bose, I., Koh, N.S., Liu, L. (2012). Manipulation of online reviews: an analysis of ratings, readability, and sentiments. Decision Support Systems 52, 674-684.

Huettner, F., Sunder, M. (2012). Axiomatic arguments for decomposing goodness of fit according to Shapley and Owen values. Electronic Journal of Statistics 6, 1239-1250.

Ingold, A., Yeoman, I., Leask, A. (2000). Yield Management: Strategies for the Service Industries. Thomson Learning, London.

Israeli, A. A. (2002). Star rating and corporate affiliation: their influence on room price and performance of hotels in Israel. International Journal of Hospitality Management 21, 405-424.

Kannan, P. K., Kopalle P. K. (2001). Dynamic pricing on the Internet: importance and implications for consumer behaviour. International Journal of Electronic Commerce 5, 63-83.

Kim, J. Y., Natter, M., Spann, M. (2009). Pay what you want: A new participative pricing mechanism. Journal of Marketing 73(1), 44-58.

Kimes, S. E., Wirtz, J. (2003). Has revenue management become acceptable? Findings from an international study on the perceived fairness of rate fences. Journal of Service Research 6(2), 125-135.

Lancaster, K. J. (1966). A new approach to consumer theory. Journal of Political Economy 74, 132-156.

Mauri, A. G., Minazzi, R. (2013). Web reviews influence on expectations and purchasing intentions of hotel potential customers. International Journal of Hospitality Management 34, 99-107.

Monty, B., Skidmore, M. (2003). Hedonic pricing and willingness to pay for bed and breakfast amenities in Southeast Wisconsin. Journal of Travel Research 42, 195-199.

Narangajavana, Y., Garrigos-Simon, F. J., García, J. S., Forgas-Coll, S. (2014). Prices, prices and prices: A study in the airline sector. Tourism Management, 41, 28-42. 
Netessine, S., Shumsky, R. (2002). Introduction to the theory and practice of yield management. INFORMS Transactions on Education 3(1), 34-44.

Núñez-Serrano, J. A., Turrión, J., Velázquez, F. J. (2014). Are stars a good indicator of hotel quality? Assymetric information and regulatory heterogeneity in Spain. Tourism Management 42, 77-87.

Owen, G. (1977). Values of game with a priori unions. In Heim, R., Moeschlin, O. (eds.) Essays in Mathematical Economics and Game Theory. Springer, New York, 76-88.

Peterson, R. (2005). "Investing Lessons from Neuroscience: fMRI of the reward system". Brain Research Bulletin, vol. 67, 391-397.

Piga, C. A., Alderighi, M., Nicolini, M. (2015). Combined Effects of Capacity and Time on Fares: Insights from the Yield Management of a Low-Cost Airline. Review of Economics and Statistics. DOI: 10.1162/REST_a_00451. (forthcoming).

Rao, V. R. (1984). Pricing research in marketing: The state of the art. Journal of Business, S39-S60.

Rigall-I-Torrent, R., Fluvià, M. (2011). Managing tourism products and destinations embedding public good components: a hedonic approach. Tourism Management 32(2), 244-255.

Ronnen, Uri. (1991). Minimum quality standards, fixed costs, and competition. The RAND Journal of economics, 22(4), 490-504.

Rosen, S. (1974). Hedonic prices and implicit markets: product differentiation in pure competition. The Journal of Political Economy 82(1), 34-55.

Roubi, S., Litteljohn, D. (2004). What makes hotel values in the UK? A hedonic valuation model. International Journal of Contemporary Hospitality Management, 16(3), 175-181.

Sanjay, K. (2009). Yield management: getting more out of what you already have. Ericsson Business Review 2, 17-19.

Shapley, L.S. (1953). A Value for n-person Games. In Contributions to the Theory of Games, Annals of Mathematical Studies 28, 307-317. Princeton University Press.

Shorrocks, A. F. (2013). Decomposition procedures for distributional analysis: a unified framework based on the Shapley value. Journal of Economic Inequality, 1-28.

Sotiriadis, M. D., van Zyl, C. (2013). Electronic word-of-mouth and online reviews in tourism services: the use of twitter by tourists. Electronic Commerce Research 13(1), 103-124.

Su, X. (2007). Intertemporal Pricing with Strategic Customer Behavior. Management Science 53(5), 726741. 
Talluri, K., Van Ryzin, G. (2004). Revenue management under a general discrete choice model of consumer behavior. Management Science 50(1), 15-33.

Thrane, C. (2005). Hedonic price models and sun-and-beach package tours: the Norwegian case. Journal of Travel Research 43, 302-308.

Thrane, C. (2007). Examining the determinants of room rates for hotels in capital cities: the Oslo experience. Journal of Revenue and Pricing Management 5, 302-308.

Tsang, A. S., Prendergast, G. (2009). Is a "star" worth a thousand words?: The interplay between productreview texts and rating valences. European Journal of Marketing 43(11/12), 1269-1280.

Urtasun, A., Gutiérrez, I. (2006). Hotel location in tourism cities: Madrid 1936-1998. Annals of Tourism Research 33(2), 382-402.

van Schaik, P., Ling, J. (2009). The role of context in perceptions of the aesthetics of web pages over time. International Journal of Human-Computer Studies 67(1), 79-89.

Vanslembrouck, I., Huylenbroeck, G., Meensel, J. V. (2005). Impact of agriculture on rural tourism: a hedonic pricing approach. Journal of agricultural economics 56(1), 17-30.

White, P.J., Mulligan, G.F. (2002). Hedonic estimates of lodging rates in four corners region. The Professional Geographer 54, 533-543.

Zhang, Z., Ye, Q., Law, R. (2011). Determinants of hotel room price: An exploration of travelers' hierarchy of accommodation needs. International Journal of Contemporary Hospitality Management 23(7), 972-981.

Yacouel, N., Fleischer, A. (2012). The role of cybermediaries in reputation building and price premiums in the online hotel market. Journal of Travel Research 51(2), 219-226. 